\title{
Pistas para entender a crise na relação entre técnicos e classes populares: uma conversa com Victor V. Valla
}

\author{
Some clues for understanding the crisis \\ in relations between working-class \\ populations and health professionals: \\ an interview with Victor V. Valla
}

Victor V. Valla nasceu em 8 de agosto de 1937 na Califórnia, Estados Unidos, na cidade de Los Angeles. Graduou-se em Educação na Saint Edward's University (1959). Ainda na Califórnia integrou, como missionário, a Ordem Religiosa Irmãos e Padres de Santa Cruz, através da qual

Departamento de Endemias Samuel Pessoa, Escola Nacional da Saúde Pública, Fundação Oswaldo Cruz. Rua Leopoldo Bulhões 1480, Rio de Janeiro, $R J$ 21041-210, Brasil. rosely@ensp.fiocruz.br chegou ao Brasil em 1964. Nessa época, em pleno regime militar, conheceu os setores progressistas da Igreja Católica no Brasil, quando teve a oportunidade de, ao mesmo tempo, freqüentar aulas de língua portuguesa e começar a ter um conhecimento crítico sobre a realidade brasileira.

Em 1966 desligou-se da ordem religiosa e ficou morando no Brasil. Na cidade de São José dos Campos, São Paulo, ministrou aulas de inglês (1967 a 1974) no Instituto Cultural Brasil Estados Unidos (IBEU) e no Instituto Tecnológico da Aeronáutica (ITA), onde conseguiu suporte para realizar estudos de mestrado e doutorado. Nessa época, através do acompanhamento de trabalhos comunitários de alguns dos alunos do curso de inglês, tomou contato, pela primeira vez, com o método Paulo Freire de educação popular.

Obteve o título de mestre em História Social do Brasil pela Universidade de São Paulo (USP) em 1969, onde também doutorou-se em História Social do Brasil (1972). Nestes anos de pós-graduação desenvolveu estudos sobre a história da influência norte-americana na economia brasileira1, sob a orientação da Dra. Nícia Vilela Luz.

Entre 1973 e 1975 trabalhou na Coordenação Econômica e Planejamento da Lavoura Cacaueira (CEPLAC), atuando na área de educação não-formal de técnicos agrícolas, agrônomos e trabalhadores rurais no Município de Ilhéus, Estado da Bahia.

Por opção, solicitou nacionalidade brasileira (1982), depois de 18 anos morando no Brasil.

Já como cidadão brasileiro, Victor Valla ingressou para o quadro de professores da Universidade Federal Fluminense (UFF) em 1975, onde, até hoje, é professor do Programa de Pós-Graduação da Faculdade de Educação. 
Foi professor/pesquisador do Programa de Pós-Graduação em Educação da Fundação Getúlio Vargas (FGV) entre 1977 e 1982, onde, entres diversos trabalhos, realizou investigação sobre a história da educação nas favelas cariocas.

É pesquisador titular da Escola Nacional de Saúde Pública da Fundação Oswaldo Cruz (ENSP/FIOCRUZ), desde 1984. Nessa instituição criou o Núcleo de Educação, Saúde e Cidadania do Departamento de Ciências Sociais (1986), passando a dedicar-se, mais especificamente, aos estudos sobre Participação Popular, Educação e Saúde. As pesquisas realizadas por este núcleo resultaram na publicação de dois livros sobre educação e participação popular em saúde que são referências obrigatórias nos cursos de saúde pública no país2,3.

Fundou, em 1990, com outros pesquisadores da Ensp e lideranças comunitárias moradoras da região dos subúrbios da Leopoldina na cidade do Rio de Janeiro, a organização não-governamental Centro de Estudos e Pesquisas da Leopoldina (CEPEL).

Desde 1993, integra a equipe interdisciplinar de pesquisadores e professores do Departamento de Endemias Samuel Pessoa da ENSP/ FIOCRUZ.

Coordena, desde o início dos anos 90, o Curso de Especialização em Educação e Saúde da ENSP/FIOCRUZ, que hoje é um dos pouco cursos desta área existentes no país.

Em 1996, buscando aprofundar seus estudos sobre a relação entre profissionais de saúde e de educação com as camadas populares, fez o pós-doutourado na University of California (1996), Estados Unidos, iniciando a produção de investigações sobre apoio social e saúde.

Juntamente com pesquisadores e militantes de movimentos sociais em saúde do país, coordenou a articulação nacional da Rede de Educação Popular (1998).

Ao longo de sua carreira acadêmica orientou várias teses de mestrado e doutorado nas áreas de educação (UFF) e de saúde pública (ENSP), publicou inúmeros artigos em revistas científicas e capítulos de livros em edições nacionais e estrangeiras e, desde 1986, publicou dez livros em editoras brasileiras.

Com uma participação bastante ativa na realização de congressos nacionais e latino-americanos nas área de saúde coletiva e de educação, Victor V. Valla também se preocupou em divulgar e debater seus estudos em outros meios que não só aqueles de circulação restrita ao meio acadêmico stricto sensu. Sempre buscou produzir livros e artigos e participar de eventos voltados para o público leigo dos movimentos populares organizados e para técnicos dos serviços de Educação e Saúde.

Em reconhecimento ao seu trabalho junto aos movimentos sociais no Rio de Janeiro recebeu, em 1996, da Câmara Municipal da Cidade do Rio de Janeiro, o título de Cidadão Honorário da Cidade do Rio de Janeiro.

A área das Ciências Sociais em Saúde no Brasil também ganhou muito com a incorporação dos estudos sobre Participação Popular, Educação e Saúde realizados por Victor V. Valla, que iniciou suas atividades de pesquisa no campo da Saúde Pública a partir da metade dos anos 80 do século XX. Neste período sempre esteve presente, contribuindo para o debate sobre as grandes transformações no campo acadêmico e na estrutura dos serviços de saúde pública no Brasil.

Esta entrevista foi realizada em duas fases (novembro de 2002 e janeiro de 2003) no Departamento de Endemias Samuel Pessoa, da ENSP/ FIOCRUZ. A versão aqui apresentada cobre apenas uma parte da riqueza do conteúdo de nossas conversas. Busquei destacar as principais preocupações intelectuais da vida e obra deste pesquisador, e cidadão militante, incansavelmente preocupado com as condições de vida e situação de saúde das grupos populares no Brasil.

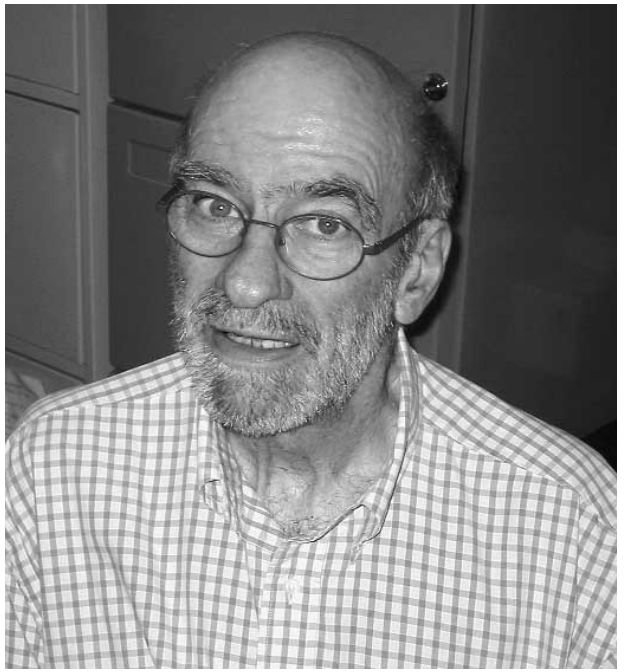

Victor V. Valla: Escola Nacional de Saúde Pública, Fundação Oswaldo Cruz, Rio de Janeiro, 2003 (foto: Leandro Carvalho). 
Rosely Valla, você tem uma formação de graduação na área de Educação nos Estados Unidos e fez seu mestrado e doutorado em História Social do Brasil na USP. Como você se aproximou do campo da Educação e Saúde e veio para a ENSP, na FIOCRUZ?

Valla Mesmo tendo formação em pós-graduação na área de História, eu sempre me mantive no campo da Educação e, principalmente, da Educação Popular, mas em uma perspectiva histórica.

Quando eu comecei a trabalhar na Fundação Getúlio Vargas, no IESAE (Instituto de Estudos Avançados em Educação), eu levei a discussão de Educação Popular para o mestrado de Educação da FGV e trabalhei com esse tema em sala de aula e, também, na orientação de dissertações. Depois de algum tempo, surgiram problemas com alguns dirigentes do Programa de Pós-Graduação que apontavam incompatibilidade do tema com a instituição, acusando os estudos de Educação Popular como "não muito científicos" e eu tive de me retirar da Fundação.

Naquele momento, eu tinha alguns alunos ouvintes, eram da ENSP, que chamaram minha atenção para o fato de que o estudo que eu desenvolvia na época, sobre Educação Popular em Favela, tratava, sem eu perceber, das mesmas questões da Educação e Saúde. Nos meus estudos, eu não me referia, diretamente, à Educação Popular e Saúde. Mas, utilizando meu livro, Educação e Favela 4 , os alunos diziam que era um livro voltado essencialmente para a Educação e Saúde.

Quando tive que sair da FGV, sugeriram que eu aproveitasse um concurso que estava surgindo na ENSP. A professora Lenita Vasconcelos estava saindo do Departamento de Ciências Sociais, por aposentadoria, e tinha aberto uma vaga para pesquisador. Muitas pessoas me encorajaram, tanto professores quanto alunos, dizendo que eu já estava no campo de Educação e Saúde, embora eu nunca tivesse encarado dessa forma.

R No seu livro, Educação e Favela, publicado em 1986, você apresenta o resultado de estudos sobre a história da educação nas favelas do Rio de Janeiro, trazendo uma crítica à atuação dos governos e da Igreja junto às classes populares na cidade. Você poderia falar um pouco dessas questões?

V Eu, recentemente, terminei um artigo para a revista Interface, que trata a Educação e Saúde como uma questão ética ${ }^{5}$. Nele eu recupero toda a metodologia do livro Educação e Favela, e caracterizo a Educação e Saúde como um movimento, essencialmente, de cima para baixo, oriundo das classes dominantes (governantes, médicos, profissionais de saúde) para as classes populares. Neste movimento estaria implícito a idéia de que as classes populares não teriam um conhecimento próprio e precisavam de uma orientação a partir das classes hegemônicas. Essa orientação ocorreria através da Educação e Saúde, como uma forma de manter as classes populares afastadas do chamado cordão sanitário.

\section{R Como uma forma de controle?}

V Sim, controle não só físico, em termos de localização mas, também, em termos de atos higiênicos. Era um movimento que tinha como pressuposto que as classes populares, justamente por serem pobres, não tinham saúde, não tinham educação. Eu coloco, no artigo, que a Educação e Saúde seria uma forma de invenção das classes hegemônicas no Brasil, como forma de controle.

Eu chamo atenção que nossa tentativa na ENSP, nesses últimos 15 anos, foi de modificar essa relação de cima para baixo, passando de um movimento vertical para um movimento horizontal.

Eu acho que esse é o eixo central dessa discussão: há um pressuposto nas classes dominantes de que as classes pobres, as classes populares, precisam de uma educação que lhes garanta uma melhor saúde. Há um ciclo vicioso: as pessoas são ignorantes e por serem ignorantes são pobres e por serem pobres não têm saúde, por não terem saúde são pobres. Enfim, um ciclo vicioso que, supostamente, seria rompido na medida em que as classes populares tivessem mais educação. Essa discussão aponta para a necessidade da participação popular, no sentido da construção da cidadania, de participação nas decisões políticas. Não se trata, portanto, de ter acesso apenas à educação formal, mas também, acesso aos bens de consumo coletivo necessários à proteção sanitária. $\mathrm{O}$ acesso a esses bens serão alcançados, principalmente, com a execução de obras governamentais, principalmente as da área de engenharia sanitária. A gente sabe que em qualquer bairro pobre onde são introduzidas obras de água potável e saneamento, a mortalidade infantil cai em pelo menos $50 \%$. Isso sem você introduzir qualquer programa de educação naquele bairro. Então, seria mais uma questão de necessidade de participação popular, de organização das pessoas para exigir que os governos revejam os gastos públicos em torno dessas carências. A melhoria das condições de vida passaria mais pela engenharia civil do que pela educação. 
R Você sempre foi um militante político junto aos movimentos sociais no Brasil e, mais particularmente, no Rio de Janeiro. Como se dá essa articulação entre a militância política e o trabalho acadêmico?

V Esta atuação política tem sido mais em torno de coisas como os Conselhos de Saúde e o Partido dos Trabalhadores (PT). Eu vejo que a discussão continua a mesma. Nossos colegas e companheiros que são membros do Partido e pessoas ligadas às chefias dos serviços de saúde têm, também, muitos dos preconceitos que nós colocamos como sendo das classes dominantes. Quero dizer, ainda continuam com a idéia de que as classes populares são ignorantes, não têm os conhecimentos necessários para ter saúde e precisam de educação.

Parte dessa minha militância política tem sido uma discordância com essa posição, tentando apontar a forma como as classes populares demonstram seus conhecimentos e como eles são importantes para que tenhamos mais clareza da realidade.

Temos apontado para a possibilidade de uma construção compartilhada do conhecimento, fazendo convergir o saber acumulado a partir da ciência com o saber acumulado pelas classes populares a partir da sua vivência. Esses dois saberes poderiam se fundir para poder criar um terceiro conhecimento. Essa tem sido uma das questões que temos levantado a partir da militância, principalmente, no PT e nos Conselhos Municipais e Distritais de Saúde.

R Então, podemos pensar a militância política também como necessária para construção metodológica do seu trabalho acadêmico. Estar militando nos movimentos sociais é uma necessidade do seu trabalho acadêmico?

V Quando eu participei da criação do CEPEL, tínhamos uma proposta de investigação das condições de vida de uma região específica, a partir da sistematização e organização de dados produzidos pelos órgãos governamentais, pelas universidades e pelos depoimentos da própria população moradora dessa região.

Essa proposta está ligada a uma preocupação da pesquisa acadêmica: a necessidade de estar junto às classes populares, nas suas reuniões ou fazendo entrevistas, de ouvir com muito cuidado o que as pessoas estão dizendo. Essa idéia faz parte de uma discussão trazida por José de Souza Martins 6 em A Crise da Interpretação é Nossa, onde ele aponta a necessidade de ouvirmos o que as pessoas estão falando, sem ver o que está sendo dito a partir de categorias já criadas por nós.
R Em 1990 você participou da criação do CEPEL e, de uma certa forma, até hoje está envolvido nas atividades dessa organização não-governamental. Você poderia falar sobre a origem deste trabalho, destacando os fundamentos dessa atuação?

V Acho que a idéia era criar um centro de documentação e pesquisa que pudesse oferecer subsídios, seja para as universidades, seja para o próprio governo, para o desenvolvimento de projetos sociais.

O nosso pressuposto era que os movimentos sociais, muitas vezes, não tinham acesso aos dados técnicos sobre os problemas que estavam reivindicando. No confronto desses movimentos com os governos, muitas vezes não havia condições de se manter um debate com os governantes e técnicos, porque os movimentos não tinham acesso aos dados que estavam sendo produzidos. Muitas vezes esse centro serviria para fornecer os dados necessários para ajudar a compreender as condições de vida, do ponto de vista popular. Os profissionais do centro poderiam produzir um conhecimento junto com as classes populares que contribuiria para o fortalecimento das organizações das classes populares na sua interlocução com os governos.

R Desde 1990, que mudanças ocorreram no trabalho de pesquisa com os movimentos populares organizados na Leopoldina? Você percebe alguma mudança de perspectiva dos grupos que você acompanha?

V Um dos problemas está ligado à manutenção do financiamento externo, porque existe um certo desinteresse dos grupos financiadores em manter este tipo de trabalho do CEPEL. Existe uma certa descrença sobre a importância deste tipo de trabalho. Outro problema é o crescimento no grau de violência, que tem dificultado o trabalho nas favelas.

Tenho percebido ainda uma preocupação crescente com a questão do meio ambiente. $\mathrm{Na}$ área da Leopoldina existe um movimento em torno dos problemas da Serra da Misericórdia, que tem crescido bastante.

R Do que eu pude acompanhar de sua trajetória de pesquisa na ENSP, avalio que houve duas pesquisas, realizadas em articulação com o CEPEL, que foram marcantes para as discussões teóricas e práticas desenvolvidas do final dos anos 80 para cá. Uma relacionada ao saneamento básico e uma outra sobre as escolas públicas, ambas na região da Leopoldina. Você poderia falar, especificamente, dessas duas experiências de trabalho? 
V Uma seria em torno da questão do saneamento básico, mais especificamente a da distribuição de água nas favelas. Foi um dado importante, inclusive, porque percebemos que os índices oficiais sobre a cobertura dos serviços de abastecimento de água na região não refletiam a realidade vivida pelos moradores da região. Observamos que a maioria das favelas localizadas nos morros que constavam, dos registros oficiais, com ligação à rede pública de água, não recebiam água todos os dias. E a administração dos serviços era realizada de forma indireta pelos moradores, através de suas associações de moradores. Estas entidades, com o tempo, passaram a ser dominadas por grupos locais de narcotraficantes que acabavam por influir na distribuição de água. Outro achado importante foi que os moradores das favelas, onde geralmente o abastecimento de água dos domicílios só era efetuado a cada dois ou três dias por semana, não exigiam que a água entrasse na rede durante as 24 horas do dia. Eles solicitavam apenas que houvesse um horário regular para a entrada de água na rede, de forma a facilitar o aprovisionamento em reservatórios improvisados ou construídos de forma permanente. Verificamos que as reivindicações junto à Companhia Estadual de Água (Cedae) ocorria por aproximações sucessivas. Como suas reivindicações eram "tratadas com um certo desprezo", eles avaliavam que era melhor "pedir aos poucos". Esta investigação resultou em uma importante contribuição para o avanço de uma série de discussões sobre a relação entre condições de vida, situação de saúde e movimentos populares.

R E a pesquisa sobre as escolas públicas?

V A outra pesquisa era sobre as condições físicas das escolas públicas: questões como os banheiros, quantas privadas havia em cada banheiro, quantos alunos havia na escola, e questões assim: quantas privadas de fato funcionavam, quantas pias havia para lavar as mãos, se tinha sabão e toalha de papel, como eram os bebedores de água dentro das escolas, qual era o tamanho do refeitório para a quantidade de alunos...

Era uma pesquisa que ia na direção da capacidade da escola pública de ser uma referência para a questão de saúde e higiene. Quero dizer, como é que você podia recomendar que os alunos lavassem suas mãos depois que usassem o banheiro, se nem o banheiro da escola tinha sabão e toalha de papel e se as pias não funcionavam?

R Desde a sua fundação, o CEPEL edita o jornal Se Liga no Sinal7. O que motivou a criação desse jornal?
V O SINAL é uma sigla que significa Sistema de Informação em Nível Local. Ele foi concebido a partir da proposta que o Betinho implantou no IBASE (Instituto Brasileiro de Análises Sociais e Econômicas). Na época, a gente estava preparando o primeiro número do Sinal, justamente quando o IBASE lançou a campanha Se Liga Rio. Transferimos essa mesma idéia para a Leopoldina, o Se Liga Leopoldina.

Tudo isso surgiu durante o período da epidemia de dengue. O Se Liga Leopoldina teve o objetivo de alertar a população para a necessidade de organização e manifestação contra a epidemia de dengue e reivindicar ações do governo. O jornal foi pensado como um dos nossos instrumentos de comunicação, onde eram divulgadas informações referentes às condições de vida na região da Leopoldina. Era um instrumento de divulgação da análise dos dados coletados de fontes diversas: governos, universidades e depoimentos da população moradora, principalmente, daquelas pessoas que participavam dos movimentos socais na região. O jornal era uma expressão do arquivo que estava sendo criado no CEPEL, que hoje tem o nome de CedVida (Centro de Documentação sobre as Condições de Vida da Leopoldina). Então, aproveitando esse centro de documentação e as pesquisas realizadas pelo CEPEL e pela ENSP, haveria um fluxo permanente de informação, trazida pela população e por outra fontes, que poderiam ser colocados nesse jornal. Essa era uma idéia que o Betinho tinha para o IBASE. Ele trabalhava com a idéia de que os funcionários das instituições e empresas federais como a Petrobras, a FIOCRUZ, a Light e também de outros órgãos de governo tinham um conjunto de informações a que a população não tinha acesso. Por isso ele criou o IBASE, para criar um fluxo de informações desses órgãos com o IBASE, para que fossem fornecidas à sociedade brasileira. Então o Sinal teve a mesma idéia, mas só na região da Leopoldina, onde você poderia ter uma rede em nível local, entre profissionais de instituições públicas, movimentos sociais e os pesquisadores do CEPEL.

$\mathbf{R}$ Essa idéia está relacionada ao que você define, em seus estudos como "capacitação técnica" dos movimentos sociais 8 ?

V A capacitação técnica é uma discussão que surgiu há alguns anos, depois do regime militar. Parte de uma avaliação de que os grupos populares, na medida da sua própria organização, exige do Estado determinadas questões e demandas que, muitas vezes, envolvem questões técnicas, às quais as classes populares muitas vezes não têm acesso. Aí coloca-se a seguinte 
questão: será que os vereadores, e os políticos em geral, e os técnicos formados pelas universidades têm informações sobre as demandas das classes populares? Será que a universidade brasileira prepara os futuros profissionais que vão lidar com as chamadas questões técnicas de um ponto de vista popular? As disciplinas trabalhadas dentro da universidade incluem essa perspectiva? Um bom exemplo é a demanda popular por saneamento básico: uma coisa é você ensinar saneamento básico dentro da universidade e outra questão é você trabalhar este tema do ponto de vista das classes populares. Então, a proposta da capacitação técnica pressupõe a possibilidade dos movimentos populares organizados terem acesso às questões técnicas que são necessárias para poder dialogar com o Estado.

E aí, nesta relação de mediação dos profissionais com as classes populares sobre as questões técnicas que surge o que chamo de "crise da compreensão" 8 . Ela desponta neste momento, nesta relação dos técnicos com as classes populares, via as questões técnicas.

Essa, para mim, é uma questão muito mais complexa do que o simples repasse de informações técnicas corretas, mesmo advindas da universidade, para as classes populares.

É preciso compreender que o conhecimento acumulado pela população na vivência dos seus problemas modifica sua demanda. É essa demanda que exige uma bagagem técnica para que possa ser negociada com o Estado. Nesse momento, o técnico só pode fazer a mediação com as classes populares organizadas se ele perceber que sua relação com elas deve incluir a compreensão da sua cultura.

R Até agora nós só falamos de sua atuação acadêmica no Brasil. Gostaria que você falasse sobre essa experiência de uma pessoa que vem de um país diferente, dos Estados Unidos, e opta por se tornar cidadão brasileiro e, ainda, acaba recebendo o título de cidadão carioca?

V Estamos em 2002 e eu já estou completando praticamente quarenta anos de vida no Brasil. Essa decisão de me tornar um cidadão brasileiro, e já são mais de vinte anos, não é uma coisa recente, é uma coisa bem remota.

Se você opta por morar em um país, você deve viver nesse país como cidadão praticante, participar das eleições, essas questões, e tendo uma cidadania que permita a você exigir seus direitos. Hoje, eu tenho filhos nascidos aqui também.

O que eu trago dos Estados Unidos, talvez, é uma clareza muito grande dos direitos dos indivíduos. Nos Estados Unidos você tem uma população muito atenta a seus direitos locais, no bairro onde mora, reivindicando do governo os seus direitos. Então, essa questão eu sinto que veio junto comigo. Embora este não fosse, necessariamente, o trabalho que eu fazia nos Estados Unidos, é uma questão que trago como uma espécie de herança.

Porém, a minha impressão sempre foi a de que a população norte-americana tem uma visão bastante restrita da política internacional dos Estados Unidos. O governo norte-americano oferece condições de vida adequada para a maior parte da população do país, mas não existe uma preocupação com as populações de outros países.

Ao mesmo tempo que eu chego no Brasil, nos anos que eu moro no Brasil, a militância cidadã vem crescendo. Vinha crescendo a preocupação com a criação de associações de moradores, principalmente a partir das experiências de São Paulo, na Zona Leste de São Paulo, e também na Baixada Fluminense, aqui no Rio de Janeiro. Eu posso dizer que eu faço parte desse movimento. Confesso que aprendi muito com os brasileiros sobre essa questão, que é uma abordagem semelhante ao que acontece nos Estado Unidos, mas é uma abordagem diferente, criada a partir das condições de vida aqui no Brasil.

R Como foi a sua graduação nos Estados Unidos?

V Era um ambiente muito despolitizado, que não me preparou de nenhuma forma para a minha vinda para o Brasil. Eu não trouxe uma série de questões políticas para o Brasil quando eu cheguei, eu trouxe um visão muito norte-americana que eu acho padrão. Uma certa preocupação que eu poderia fazer alguma coisa na questão da pobreza e dos pobres no Brasil. Eu acho que a minha graduação não me preparou para isso, não me ofereceu uma discussão política onde eu pudesse me preparar para compreender o mundo em que eu estava vivendo. Enquanto eu estava fazendo a graduação, ou bem perto da graduação, ocorreu a Revolução Cubana, e não tive nenhum acesso a discussões que pudessem ajudar a compreender o que estava ocorrendo. Aliás, eu não tive nenhum acesso a informações que ajudasse a compreender a história dos Estados Unidos de uma forma crítica. Isso, eu posso confessar, adquiri no Brasil.

Surpreendentemente, foram os brasileiros que me ajudaram nisso. Então, eu acho que a minha graduação me preparou, em um sentido mais amplo, no estudo das humanidades, mas não me preparou de uma forma política. Isso 
foi uma coisa que eu adquiri no Brasil, na medida em que fui convivendo com uma discussão mais complexa sobre a pobreza. Quando cheguei no Brasil, fui muito influenciado pela igreja católica mais crítica, que me ajudou a compreender melhor a questão da pobreza e a questão da relação com os Estados Unidos.

R Na sua chegada no Brasil, você foi morar em São Paulo e inicialmente trabalhou dando aulas de inglês no ITA. Como foi essa coisa, de ter uma atuação numa instituição militar e, ainda, conseguir se articular num trabalho de educação popular junto com grupos da esquerda?

V Esse é um momento curioso, cheio de contradições. Quando eu comecei a morar no Brasil, eu morei em São Paulo e comecei a dar aulas de inglês no IBEU. Aos sábados pela manhã dava aulas para alguns profissionais de engenharia, e um deles me disse que havia uma vaga para professor de inglês no ITA. Ele me levou para o ITA para conhecer e em seguida eu comecei a trabalhar lá.

O ITA, naquela época, tinha, acho que tem até hoje, um departamento de humanidades, onde fui convidado a dar aula de inglês. No convite havia a seguinte idéia: você pode dar aulas de inglês, você vai ser pago por isso. Agora, se você quiser, você pode dar outras disciplinas também, e se você quiser também pode fazer seu mestrado ou doutorado em São Paulo. A viagem seria uma viagem curta; uma hora e pouco.

$\mathrm{Na}$ época, eu estava muito interessado em História e, verifiquei que era possível fazer mestrado em História da Civilização Brasileira com o Sérgio Buarque de Holanda e outros professores. Eu comecei a aproveitar meu interesse por História para oferecer pequenas disciplinas no ITA sobre História do Brasil, História Contemporânea. Isso ocorreu durante a ditadura militar, e, assim mesmo eu comecei a levantar discussões sobre fascismo, comunismo, nazismo, desigualdade social no Brasil. Os alunos tinham muito interesse, encheram minhas aulas e eu comecei a trabalhar com isso. Esses alunos que freqüentavam minhas aulas também tinham trabalho comunitário ao redor do ITA, nos bairros pobres e me convidaram para participar desse trabalho, foi aí que eu tive contato com o método Paulo Freire. Descobri que até 1964, isso foi em 1967, o ITA havia sido um importante centro do movimento estudantil para todo o Vale do Paraíba. O instituto sempre recebia alguns alunos da classe média com tendências progressistas, que tinham uma discussão política desenvolvida e alto grau de conhecimento que permitia que passassem na seleção do ITA, que é muito rigorosa.
Eu, como norte-americano relativamente recente de moradia no Brasil, fui aprendendo muitas coisas por esses movimentos que tinham suas vinculações por São Paulo - que também estava começando um movimento muito grande em torno das questões dos bairros, da Educação Popular, do método Paulo Freire. Isso tudo faz parte da minha aprendizagem, do meu passado, confesso que aprendi muita coisa sobre Educação Popular nessa época.

R Como que era tudo isso, na época de ditadura militar, o movimento estudantil, a política...

V Isso que sempre me surpreendeu. O ITA sempre foi preservado nessas contradições, embora tivessem muitos problemas lá fora, dentro do ITA não havia problemas entre o trabalho desenvolvido pelos alunos e o regime militar.

R Isso ocorreu mais ou menos em que período? V Foi a partir de 1967. Eu saí do ITA em 1972, mas eu soube que depois de 1972 ocorreram alguns problemas com alunos que estavam desenvolvendo trabalhos em São José dos Campos junto com os sindicatos de metalúrgicos.

R Como foi a decisão de morar no Brasil? V Nos Estados Unidos eu era ligado a uma ordem religiosa que trabalhava em nível de segundo grau. Essa ordem tinha trabalhos missionários na África, na Índia e, também, no Brasil. Na região onde eu morava nos Estados Unidos, que na época era a Califórnia, a Ordem tinha trabalho missionário no Brasil. Eu aproveitei essa oportunidade e solicitei minha vinda ao Brasil, dentro dessa perspectiva de trabalho missionário.

Ironicamente, eu vim para o Brasil justamente em 1964. Obviamente, meu grau de politização era muito reduzido quando eu cheguei e, para aprender português, eu fiz o que eles chamavam de curso de adaptação cultural com um setor da Igreja Católica Progressista. Foi aí que eu aprendi português e, também, aprendi muito sobre a realidade brasileira, com os franciscanos em Petrópolis.

\section{R Eram ligados à Teologia da Libertação?}

V Não. Naquela época era simplesmente a preocupação das pessoas com a ditadura militar, com a perseguição das pessoas. Nesse curso eu aprendi português e também "realidade brasileira”. Tinham muitos padres progressistas fugidos da perseguição militar que saíam do Rio e iam para Petrópolis. Durante a noite, eles ficavam explicando para todos o que estava 
acontecendo. Aí foi onde eu realmente comecei a compreender politicamente a realidade brasileira. Esse foi um grande passo para mim.

Posso confessar que, obviamente, eu não trouxe essa discussão dos Estados Unidos, eu vim com muitos preconceitos: ajudar os pobres, caridade, essa coisa assim. Na realidade eu não tinha essa clareza que me foi apresentada na época.

Foi dessa forma que eu cheguei no Brasil: como membro da Ordem Religiosa chamada de Irmãos e Padres de Santa Cruz. Um tempo depois de terminar a formação e começar a trabalhar no Brasil, eu decidi me afastar da ordem religiosa e ficar aqui. Eu me desvinculava da ordem e, naquele momento, poderia ter voltado para os Estados Unidos. Eu decidi voltar ao Brasil por minha conta. Aí, foi quando eu comecei a ter esse contato com a escola de inglês, uma maneira de me manter, que me levou para o ITA e fui fazer toda a minha pós-graduação, mestrado e doutorado. Daí em diante nunca deixei de trabalhar nas universidades brasileiras, já tinha conseguido a formação para isso.

Então, eu faço parte de uma geração, que não é pequena, que tem as credenciais no sentido de mestrado e doutorado e que tem essa forte preocupação social sobre papel das universidades. Eu posso dizer que eu não sou uma exceção, têm muitas pessoas que já trabalham com esta questão. Eu posso dizer aqui: eu já citei José de Souza Martins, José Álvaro Moisés, Lúcio Kowaric. Tem pessoas que vêm fazendo isso há anos.

Eu sempre achei que minha vinda para o Brasil foi melhor para mim. Foi uma coisa muito boa porque foi aqui que eu consegui minha formação acadêmica através da USP, no Departamento de História. Aqui, eu consegui, enquanto eu estudava na USP, me manter através do ITA, e com o tempo eu fui para outras instituições, com essa mesma preocupação. Posso dizer que sempre foi aberto para mim situações que me enriqueceram muito. Eu sou muito grato pelas oportunidades para mim oferecidas, dentro das necessidades das universidades brasileiras de ter quadros com formação acadêmica. Eu sempre sou grato aos brasileiros por, pacientemente, me explicar a realidade brasileira.

R Atualmente, quais são os temas de maior preocupação em seus estudos?

V Na realidade, eu continuo com duas linhas de pesquisa. Uma voltada para a questão da "Religiosidade Popular e Saúde", que é uma das linhas de pesquisa que tem vários orientandos, no doutorado e no mestrado, trabalhando co- migo ${ }^{9}$. Tem me interessado muito a discussão sobre o crescimento das igrejas evangélicas e pentecostais no Brasil. Para mim esse tema é uma questão de saúde, porque é onde podemos entender a busca das classes populares por algum tipo de apoio sistemático às suas difíceis condições de vida. A outra linha, que de certa forma está relacionada à primeira, é sobre "Saúde e Pobreza". Esta pesquisa, que vem sendo construída em conjunto com alguns técnicos da FIOCRUZ, busca compreender quais são as relações entre a crise econômica e a saúde no Brasil. A idéia do projeto é fugir um pouco da crença de que a crise econômica é um problema muito complicado. Nossa proposta é relativamente simples e tem como material de pesquisa alguns suplementos de economia de jornais diários, revistas de organizações nãogovernamentais e partidos políticos que tratam da questão da crise econômica. A idéia é buscar apropriar-se da discussão sobre a crise econômica, sem necessariamente contar com um grupo de economistas de "alto gabarito".

R Uma tentativa de construir uma outra possibilidade de interpretação da crise, que não aquela da economia clássica...

V Na verdade, tem um paralelo com a pesquisa sobre saneamento básico nas favelas da Leopoldina, que foi realizada no CEPEL. Não tenho formação na área de saneamento básico mas, hoje, eu acho que consegui me apropriar da questão da água nas favelas. Esta é a idéia da pesquisa: como você, como leigo, se apropria de determinados temas, embora você também seja pesquisador?

Obviamente, há uma relação com a questão da religiosidade, pois eu acho que a busca das classes populares por essas igrejas é uma busca de fugir desta crise através do apoio que recebem destas igrejas, tentando resolver seus problemas de saúde, por exemplo. Não sei se eu estou levando a discussão corretamente, mas, eu tenho notado, a partir de depoimentos de técnicos e de pesquisadores da saúde, uma preocupação com o que eles chamam de "sofrimento difuso”. Este é um termo utilizado para se referir ao grande sofrimento da população pobre quando vai buscar ajuda no Centro de Saúde, apresentando queixas de dores no corpo, dores na cabeça e todo tipo de dor que carregam com suas preocupações com a questão da pobreza, violência, salário mínimo. Esse "sofrimento difuso", talvez possa explicar por que as pessoas buscam esse suporte nas igrejas evangélicas e pentecostais.

Acredito que, de novo, nós estamos diante de outro problema com a educação e saúde, de 
que começamos a falar no início dessa entrevista. Estamos lidando com os preconceitos da classe dominante em relação às classes populares, a questão da pobreza, higiene, educação e tudo isso, esses tipos de preconceitos.

Em geral, as pessoas de classe média e muitos pesquisadores dizem que não têm de observar o que está acontecendo com a ida das classes populares paras essas igrejas. Acham que são apenas espaços de manipulação, para tirar dinheiro da população. As perguntas que fazemos são as seguintes: será que é só isso que as classes populares percebem nesses espaços? Porque que insistem em freqüentar esses espaços? Em busca de que tipo de apoio? Estas perguntas são elaboradas, dentro de uma perspectiva de que as classes populares não são "bobas" ou "inocentes". Elas têm um conhecimento que permite enfrentar todos os problemas do dia-a-dia. Percebem isso e insistem nisso. E por que há tantos preconceitos sobre esses movimentos.

R Você poderia falar, mais detalhadamente, como chegou nos estudos sobre Religiosidade e Saúde?

V Tudo isso tem sua origem, a meu ver, na questão de Educação e Saúde, na Educação Popular, na questão da Participação Popular. Eu acho que é esse conjunto de campos que deram origem a essa discussão, que é, essencialmente, uma preocupação sobre a comunicação entre os profissionais de educação e saúde e as classes populares. Será que esses profissionais estão conseguindo entender as classes populares, seja nos serviços, seja nos trabalhos comunitários.

O que motivou esta preocupação foram os artigos e trabalhos de José de Souza Martins 6 e Marilena Chauí10, em que eles questionam se não haveria uma crise de compreensão da parte dos profissionais, pesquisadores e militantes em relação ao que é dito e praticado pelas camadas populares da população. Será que, de fato, estamos entendendo o que as pessoas estão fazendo e falando nas suas vidas, no seu trabalho comunitário, sobre seus problemas com a questão da saúde?

Diante desta perspectiva, estamos questionando se, no meio desta dificuldade de se compreender o que está se passando, se não haveria uma relação com a questão da religiosidade popular.

Essa é uma discussão que vem crescendo muito, não só na América Latina, mas também nos Estados Unidos e na Europa Ocidental: a recorrência a formas alternativas de saúde para resolver a grande insatisfação das pessoas com o tratamento biomédico. Dentre essas formas alternativas de lidar com a saúde, tem aparecido a religiosidade, que não é somente a religiosidade popular, mas uma questão que surge no mundo inteiro sobre a cura pela religião.

$\mathbf{R}$ Seria a religiosidade uma forma de conhecimento?

V Isso. É uma discussão que tem sua origem numa categoria utilizada por alguns pesquisadores da área da saúde nos Estados Unidos, se chama social support ou apoio social.

A primeira vez que eu atentei para isso, foi quando eu estava fazendo o pós-doutorado e vi os estudos sobre as igrejas negras no sul do Estados Unidos. Recentemente, tivemos a visita de um professor americano, que está pesquisando essa questão no Brasil, e ele disse que, nos Estados Unidos, alguns pesquisadores já têm questionado se a melhoria da saúde através da religião se dá por causa da terapêutica. Muitos pesquisadores têm assumido a posição de que a cura é religiosa, sim, e não apenas terapêutica.

R Essa cura religiosa estaria extremamente relacionada com o ritual religioso e não com questão do apoio social, com a (re)ligação entre as pessoas?

V Sim. Haveria uma certa tendência de deixar de relacionar a cura com o apoio social e colocar a questão como religiosa mesmo.

R E qual é a leitura que eles fazem dessa terapêutica?

V Não dão ênfase exclusivamente na terapêutica. Eles acreditam que, geralmente, para se proteger das críticas dentro do campo científico, sempre acabavam construindo uma explicação dentro do campo da terapêutica, do apoio social. Eles afirmam que está crescendo uma posição que admite a cura religiosa, no campo do Sagrado.

Soube de um pesquisador brasileiro, chamado Paulo Bonfatti, que fez dissertação de mestrado na Universidade Federal de Juiz de Fora, que é uma das poucas universidades Brasil com um programa de pesquisa sobre a questão da religiosidade. Aliás, o programa de pósgraduação de lá é muito bem conceituado pelo CNPq (Conselho Nacional de Desenvolvimento Científico e Tecnológico) e pela CAPES (Coordenação de Aperfeiçoamento de Pessoal de Nível Superior). O trabalho dele é sobre a Igreja Universal do Reino de Deus, e foi publicado no livro A Expressão Popular do Sagrado, que ganhou um Prêmio Jabuti. A tese de doutorado dele, ainda não publicada, tem o título de $X \hat{o}$ 
Satanás e, também, é um estudo sobre as curas na Igreja Universal do Reino de Deus. Entendo que são trabalhos que caminham na direção apontada pelo pesquisador americano de que lhe falei.

O que eu pude entender dessas afirmações é que alguns pesquisadores têm buscado a pista para explicação da cura através dos rituais que levam as pessoas ao transe, como na umbanda, no candomblé e também em algumas igrejas pentecostais. Nesses momentos, os corpos das pessoas ficam completamente relaxados, sem interferência externa.

Confesso que não compreendo muito bem isso. Sempre trabalhei a prática religiosa dentro de um campo da terapêutica que, de uma certa forma, permite me calçar no mundo científico para me proteger dentro da academia. Ainda mais em um lugar dominado pela biomedicina.

R Você vai muito mais na vertente do apoio social?

V Sim, da cura terapêutica.

R Deixe-me ver se entendi. A terapêutica é definida como uma parte da medicina que estuda e põe em prática os meios adequados para aliviar e curar os doentes. Assim, o apoio social é visto como um desses meios adequados para aliviar e curar as doenças. Não que, necessariamente, fosse um meio colocado a disposição pela medicina, mas como um meio que está disponível no ambiente das relações e, também, da prática religiosa. É nesse sentido que você discute o apoio social?

V Sim. Eu faço parte de uma associação chamada ANPEd (Associação Nacional de Pesquisa Pós-Graduação em Educação) há 15 anos e há três anos, faço parte, como coordenador, do Grupo de Trabalho de Educação Popular. Foi aí que eu introduzi minhas discussões sobre Religião e Saúde. No debate com esse grupo tenho percebido alguns problemas relacionado a dois pontos. O primeiro, com o qual tenho me identificado vê essa discussão no campo da fé. O segundo ponto tem a ver com o que tenho chamado de "questão de foro íntimo".

Acredito que o pesquisador que trabalha com a questão da Religiosidade e Saúde não, necessariamente, tenha que ser um crente, no sentido que pertença a uma religião mas, ele pode propor compreender a fé dos outros. Concordando ou não com essa fé, que é fé dos outros, podemos nos esforçar para compreendêla como uma lógica que desencadeia determinadas ações, em pessoas determinadas.
R Na verdade, compreender a fé dos outros poderia nos levar a entender quais são os caminhos escolhidos pelas pessoas para a solução de seus problemas no dia-a-dia.

V Isso. Pode ajudar a entender a maneira como elas compreendem e agem no mundo.

Eu tenho uma amiga no Grupo de Trabalho de Educação Popular da ANPEd que, toda vez que nos reunimos em Caxambu, levanta questões sobre a presença da mulher popular das classes populares dentro das igrejas pentecostais. Ela sempre aponta que mulheres não estão sendo subservientes aos pastores. Todo o ano eu levanto a mesma questão a ela, e cito uns cinco ou seis livros mostrando o progresso das igrejas pentecostais, e ela se recusa a ler os livros para debater comigo. E é uma questão de preconceitos sobre essas questões presentes em nossa academia, que é muito voltada para a ciência como a explicação do mundo. Acho que a questão religiosa questiona que a ciência seja a única explicação do mundo. Quem vem trabalhando muito com isso é a Madel Teresinha Luz, da UERJ (Universidade do Estado do Rio de Janeiro), só que no campo das terapias tradicionais como a medicina oriental, homeopatia...

Eu passei a estudar esse tema porque eu acredito que a transformação da sociedade brasileira passa por uma participação intensa das classes populares junto com o que eu chamo de mediadores - que são os técnicos, profissionais, políticos, religiosos...

Minha razão para entrar nessa discussão da religião e saúde é que eu acho que os mediadores têm uma dificuldade muito grande de compreender o raciocínio das classes populares na sociedade brasileira, o tipo de conhecimento produzido por elas. Uma das áreas que eu acho mais difícil para nós da classe média, de formação universitária (profissionais, técnicos, políticos...) é compreender a questão religiosa dentro das classes populares. Eu vejo como o Cristian Parker afirmou em um Congresso lá no Chile, que a religião é um componente da cultura popular e é por essa razão que eu proponho trabalhar com esse temall.

R Recentemente vem sendo retomada, com muita força, uma discussão, tanto no meio acadêmico como nos serviços de saúde, sobre a implementação de ações no campo da Promoção da Saúde. Nos textos que tenho lido observo a discussão da promoção da saúde tem se centrado em propor ações de educação e saúde. Como você tem visto isso? Como isso se relaciona com o seu trabalho?

V Eu confesso que tenho dificuldades com a questão da promoção da saúde. Eu tenho parti- 
cipação num livro organizado pelo Paulo Buss, onde escrevi um capítulo sobre participação popular e promoção da saúde12. Mas eu sempre tenho a sensação que a promoção da saúde tende a empurrar a questão da saúde em cima dos indivíduos na sociedade. É como se estivesse ocorrendo um novo debate onde a promoção em saúde propõe que as pessoas da sociedade se responsabilizem por sua saúde. Acho que tende também a afastar o Estado como responsável pela questão da saúde. O que tenho proposto, no campo da Educação e Saúde, é responsabilidade do poder público pela saúde da população. A promoção da saúde, como tem sido colocada, me passa uma idéia de afastamento dessa questão.

Em um seminário que fizemos no Curso de Especialização em Educação e Saúde, o José Wellington, que é professor na ENSP, mostrou que os grupos preocupados com a promoção da saúde têm dificuldade em propor essa discussão para os países pobres e acabam se afastando dessa discussão. Esta constatação foi feita em um grande congresso sobre Promoção da Saúde realizado no Canadá, que contou com a participação de profissionais de diversos países.

Então, o que eu tenho de dificuldade com a promoção da saúde está em entender quem está atrás dessa proposta e como encarar isso em relação aos países pobres.

Essa discussão me lembra um episódio ocorrido durante a Rio 92, quando os coordenadores do evento descartaram a discussão das grandes cidades do Terceiro Mundo. Felizmente, um grupo ligado ao Fórum Nacional da Reforma Urbana propôs essa discussão e realizou um seminário antes de começar o Rio 92, no Hotel Glória. Os coordenadores da Rio 92 argumentavam que não havia mais jeito para as grandes cidades. Então, é a mesma sensação que eu tenho com as questões trazidas pela chamada promoção da saúde. Elas acabam por se afastar dos problemas dos países pobres. Basta lembrar que, quando falamos de países pobres, estamos lidando com mais de $50 \%$ da população do mundo.

R Neste contexto de transferência de responsabilidade dos governos, como você vê o papel das ONGs?

V Essa é uma discussão longa que não sei se vamos ter tempo de desenvolver aqui.

As ONGs não deveriam ter uma ação de substituição das atividades do Estado. Vejo as ONGs como uma espécie de fiscal civil que deveria desenvolver trabalhos de acompanhamento das ações dos governos municipais, estaduais e federais. Esse é o trabalho de uma
ONG, não é substituir o Estado, é fiscalizar o Estado, acompanhar o Estado, acompanhar o trabalho que o Estado desenvolve. Acho que este deveria ser, também, o papel das universidades, utilizando os conhecimentos e recursos que tem para fazer esse tipo de trabalho, fiscalizar e propor alternativas.

Eu sempre gostei de um exemplo dado por integrantes da ONG PelaVidda, numa conversa sobre saúde pública. O PelaVidda mostrou que tinha, em mãos, mais dados sobre o problema da AIDS no Brasil do que o próprio Ministério da Saúde. Então eles disseram o seguinte: "Por que nós temos que ir para a Alemanha, França, Áustria, Estados Unidos buscar recursos para sobreviver, se o que nós temos em mãos é superior ao que o governo federal tem? Por que o governo federal não nos financia para fazer esse trabalho? Por que não passam recursos para nós, se estamos fazendo melhor do que ele consegue fazer em torno da questão da AIDS? Por que os recursos públicos não são distribuídos $e$ não são montados conselhos, com participantes da sociedade civil, para fiscalizar a aplicação do dinheiro no trabalho das ONGs?"

É assim que eu vejo o papel das ONGs. Não sou contra elas receberem dinheiro público. Sou contra a ONG substituir o governo e, se por acaso, receber dinheiro público, tem de ser fiscalizado. Tem de montar um conselho para fiscalizar a aplicação desse dinheiro, como deve ser feito com o próprio Estado.

R A epidemia de dengue ocorrida no final da década de 80, início da década de 90 acabou provocando um momento de crise de legitimidade dos governos que não tinham um trabalho de vigilância epidemiológica eficaz que conseguisse conter a expansão da doença. Você já levantava a discussão sobre a responsabilidade do Estado pela expansão dos bens de consumo coletivo, como saneamento básico, habitação, transporte... Nesse início do século XXI, o dengue é um importante problema de saúde pública no Brasil e, cada vez mais, se vê intensificar um discurso de "culpabilização da vítima”, que você vem criticando desde a epidemia de 1986 no Rio de Janeiro. Você poderia falar um pouco desta questão?

V Eu sempre fui muito atento à essa discussão da responsabilidade do Estado e à facilidade com que os governantes colocam a culpa na população pela expansão das doenças. Aliás, uma das posições que eu venho mantendo por muito tempo é que, quando o Estado chega a um momento em que não consegue dar conta de determinados problemas, passa a envolver a população no combate direto das doenças. E, 
na medida em que os problemas não são resolvidos, os governos passam a responsabilizar os indivíduos, na sociedade, por suas causas.

No caso do dengue, eu acho que isso vem se tornando constante. Para mim, o problema do dengue é, uma questão, especialmente, de saneamento básico. A população não pode ser culpada por esse problema. É o Estado que tem a obrigação de investir pesadamente na área de saneamento básico, na prevenção, na coleta de lixo, abastecimento de água, habitação... Aí, do meu ponto de vista, o que está em discussão é qual é a vontade política do Estado em investir, de fato, nessas áreas13.

R Tendo em vista essa nova conjuntura política que estamos vivendo no país, de ter eleito um presidente originário das classes populares, e com propostas para elas, que perspectivas você vê para o seu campo de atuação?

V Eu vejo esse novo governo assumindo um papel que deixou claro que, caso ganhasse as eleições, ia andar nessa direção. Eu acho que o governo está buscando ter uma credibilidade com os setores internacionais e nacionais.
O governo que assumiu tem clareza dos problemas que está enfrentando, e que deve enfrentá-los, inicialmente, com cautela. Eu acredito que a relação do governo com aos bancos internacionais, FMI (Fundo Monetário Internacional) e a nossa dívida externa são problemas muito sérios, para os quais o governo está se preparando para encarar.

A minha opinião é que o atual governo precisa estar pronto para desenvolver o que eu chamo de uma proposta pedagógica. Por exemplo, quando o FMI faz uma cobrança de determinadas dívidas que podem atrapalhar a campanha Fome Zero, nosso governo precisa ir para a televisão para esclarecer essas questões para a população, informando se existe dinheiro disponível para pagar as dívidas e quanto de recurso existe para desenvolver os programas sociais que está propondo. Diante da pressão dos órgãos internacionais para resolver impasses como esse é que o governo deve desenvolver uma proposta pedagógica.

\section{Referências e notas}

1 Os estudos realizados nesta época por Victor V. Valla resultaram na publicação do livro A Penetração Norte-Americana na Economia Brasileira, 1898-1928, pela editora Ao Livro Técnico S/A, em 1978.

2 VALLA, V. V. \& STOTZ, E. N., 1997. Participação Popular, Educação e Saúde: Teoria e Prática. Rio de Janeiro: Relume-Dumará.

3 VALLA, V. V. \& STOTZ, E. N., 1996. Educação, Saúde e Cidadania. Petrópolis: Editora Vozes.

4 VALLA, V. V., 1986. Educação e Favela. Petrópolis: Editora Vozes.

5 O artigo citado encontra-se no prelo e foi intitulado Construindo a Resposta à Proposta de Educação e Saúde no Brasil. 
6 MARTINS, J. S., 1989.Caminhada no Chão da Noite. São Paulo: Editora Hucitec.

7 O jornal Se Liga no SINAL é publicado, ininterruptamente, desde 1990. Com uma tiragem trimestral de 2.500 exemplares, esse periódico é voltado para um público de moradores atuantes nos movimentos populares da região, professores de escolas públicas e de serviços locais de saúde. Está voltado para a difusão de informações sobre os resultados das pesquisas na região da Leopoldina, discussão da conjuntura local e nacional e atuação de grupos organizados.

8 VALLA, V. V., 1997. Participação popular e saúde: A questão da capacitação técnica no Brasil. In: Participação Popular, Educação e Saúde: Teoria e Prática (V. V. Valla \& E. N. Stotz, org.), Rio de Janeiro: Relume-Dumará.

9 Alguns dos resultados desses estudos podem ser encontrados em: VALLA, V. V., 2001. Globalização e saúde pública no Brasil: A busca da sobrevivência pelas classes populares via questão religiosa.
In: Saúde nas Palavras e nos Gestos. Reflexões da Rede de Educação Popular e Saúde (E. M. Vasconcelos, org.), pp. 39-61, São Paulo: Editora Hucitec; VALLA, V. V., 2001. Cultura Popular e Religião. Rio de Janeiro: Editora DP\&A.

10 CHAUÍ, M., 1990. Cultura e Democracia: O Discurso Competente e Outras Falas. São Paulo: Cortêz Editora.

11 Debate realizado durante apresentação oral de trabalho sobre "Pobreza, emoção e saúde: Uma discussão sobre pentecostalismo e saúde no Brasil", durante o IX Congresso de Alternativas Religiosas na cidade de Santiago no Chile, em 2001.

12 VALLA, V. V. \& STOTZ, E. N., 1998. Desenvolvimento de habilidades pessoais. In: Promoção da Saúde e a Saúde Pública (P. M. Buss \& J. R. Ferreira, org.), Rio de Janeiro: Editora Fiocruz.

13 Estudos e debates sobre participação popular educação e saúde e o controle de endemias foram organizados por V. V. Valla em publicação especial de Cadernos de Saúde Pública (v. 14, sup. 2) em 1998. 